\title{
Jacques Hadamard in China
}

\section{by Wenlin $\mathrm{Li}^{*}$}

In the nineteen-thirties, academic exchanges with Western countries were becoming increasingly active in China. It was a period in the development of mathematics in modern China of which a significant feature was the invitation of leading mathematicians from the United States and Europe to lecture in China. Among these was Jacques Hadamard (1865-1963) of France. In this article, Hadamard's visit, its background, and its influence are discussed on the basis of existing sources.

\section{Background of Sino-French Mathematical Exchanges}

Mathematical exchanges between France and China could be traced back to the late 19th century. In 1887, two students, Tseng-Fong Ling (林振峰) and Cheou-Tchen Tcheng (郑守筬) were sent by the Fuzhou Naval College to l'École Normale Supérieur in Paris where they eventually obtained their bachelor degrees in science in 1890. That is the first record (obtainable from existing sources) of Chinese students receiving an advanced education in mathematics in France.

The mathematical exchanges between China and the West were accelerated by the 1911 revolution. In particular, the so-called Société Chinoise d'Education Rationnelle Francaise set up in 1912 helped thousands of young Chinese to come to France to receive higher education. Up to 1920, among the 2000 or so Chinese students who studied in French universities by the Work-Study Program or in other ways, four obtained their master degrees in science: Jianbai Guo (郭坚白, Université de Paris, 1916), Lu He (何鲁, Université de Lyon, 1919), Zixie Duan (段子䝨, Université

\footnotetext{
* The Academy of Mathematics and Systems Science, Chinese Academy of Sciences, Beijing

E-mail: wli@math.ac.cn
}

de Lyon, 1920) and King-Lai Hiong (熊庆来, Université de Montpellier, 1920). From 1920 onwards, the material conditions for overseas Chinese students improved, and there appeared special institutes such as l'Institut Franco-Chinois de Lyon, which became a center for Chinese students and produced, from 1920 to 1930, the first batch of Chinese doctorates in mathematics in France: Chou-Chi Yuan (袁久祉, 1927), Tsin-Yi Tchao (赵进义, 1928), Wui-Kwok Fan (范会国, Université de Paris, 1929), and Tsyun-Hyen Liou (刘俊贤, 1930); as well as master degrees in mathematics: Yanxuan He (何衍璇, 1924), Jinmin Chen (陈荩民, 1925) and Cuimin Shan (单粹民, 1926).

All the students mentioned above returned to China after finishing their studies in France and played an active role as forerunners in the development of modern mathematics in China. Most of them had led the newly established departments of mathematics in Chinese universities, among these being Tsinghua University, Peking Normal University, Central University in Nanking, and Sun Yat-sen University in Canton. In particular, King-Lai Hiong, who was later to be involved in Hadamard's visit to China, had been responsible for the establishment in 1921 of the department of mathematics at South-East University (now Nanking University), and was appointed head of the department of mathematics at the Tsinghua University in 1928. Hiong returned to France in 1930 for his degree of doctorat ès sciences mathématiques, with a dissertation on entire functions and meromorphic functions. In 1934, he returned China to resume his responsibility as head of the department of mathematics at Tsinghua, where he stayed till he was appointed as president of Yunnan University in 1938.

The first French mathematician ever to visit China was the statesman Paul Painlevé (1863-1933). In 1920 Painlevé led thither a French delegation including the mathematician Emile Borel (1871-1956), presi- 


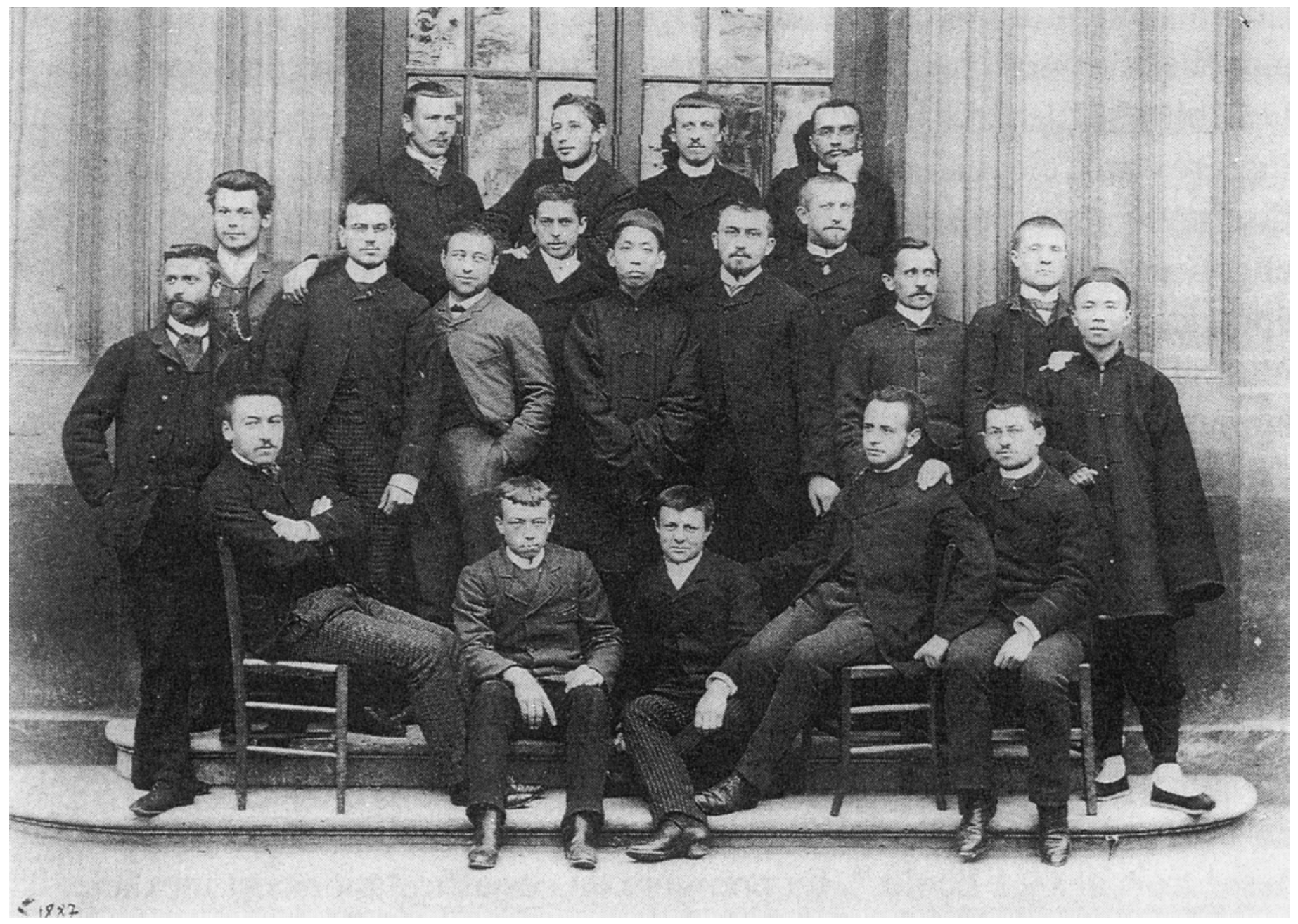

Figure 1. Chinese students at l'École Normale Supérieur, 1890. Tseng-Fong Ling stands at center. Photo courtesy of J.-C. Martzloff.

dent of l'École Normale Supérieur. Painlevé had twice been the Prime Minister of France-in 1917 and in 1925. Though this official visit was not mainly aimed at the mathematics, Painlevé's speech at the Chinese Society of Sciences in Shanghai, in which he appealed to Chinese scholars to organize societies in their own specialized fields, stimulated Chinese mathematicians to establish in 1936 the Chinese Society of Mathematics, of which almost all Chinese students returned from France were founding members.

After Painlevé and Borel, there is no record of any French mathematician visiting China till the coming of Jacques Hadamard about 16 years later.

\section{A Master in Mathematics}

Hadamard was over seventy, and enjoyed worldwide reputation as a great mathematician, when he visited China in 1935.
Hadamard's early work had been on the theory of analytic functions. In his 1892 dissertation entitled Essai sur l'étude des fonctions donées par leur development de Taylor, he had introduced set theory into the research on theory of functions of a complex variable $i$. A series of essential results obtained by Hadamard himself along this line laid ground for the theory of analytic functions.

In 1896 Hadamard had proved-on the basis of the theory of entire function, and independently of de la Vallée-Poussin-the theorem of prime numbers. His proof was a great triumph in the history of analytic number theory in the nineteenth century.

After his original work on the theory of functions of a complex variable, Hadamard began to focus his research on the real field, and in particular partial differential equations. He clarified the implications of the so-called "problem for determining solution," defined the notion of a well-posed problem (existence, uniqueness of solutions, continuous dependence on the data), constructed fundamental solutions as uni- 


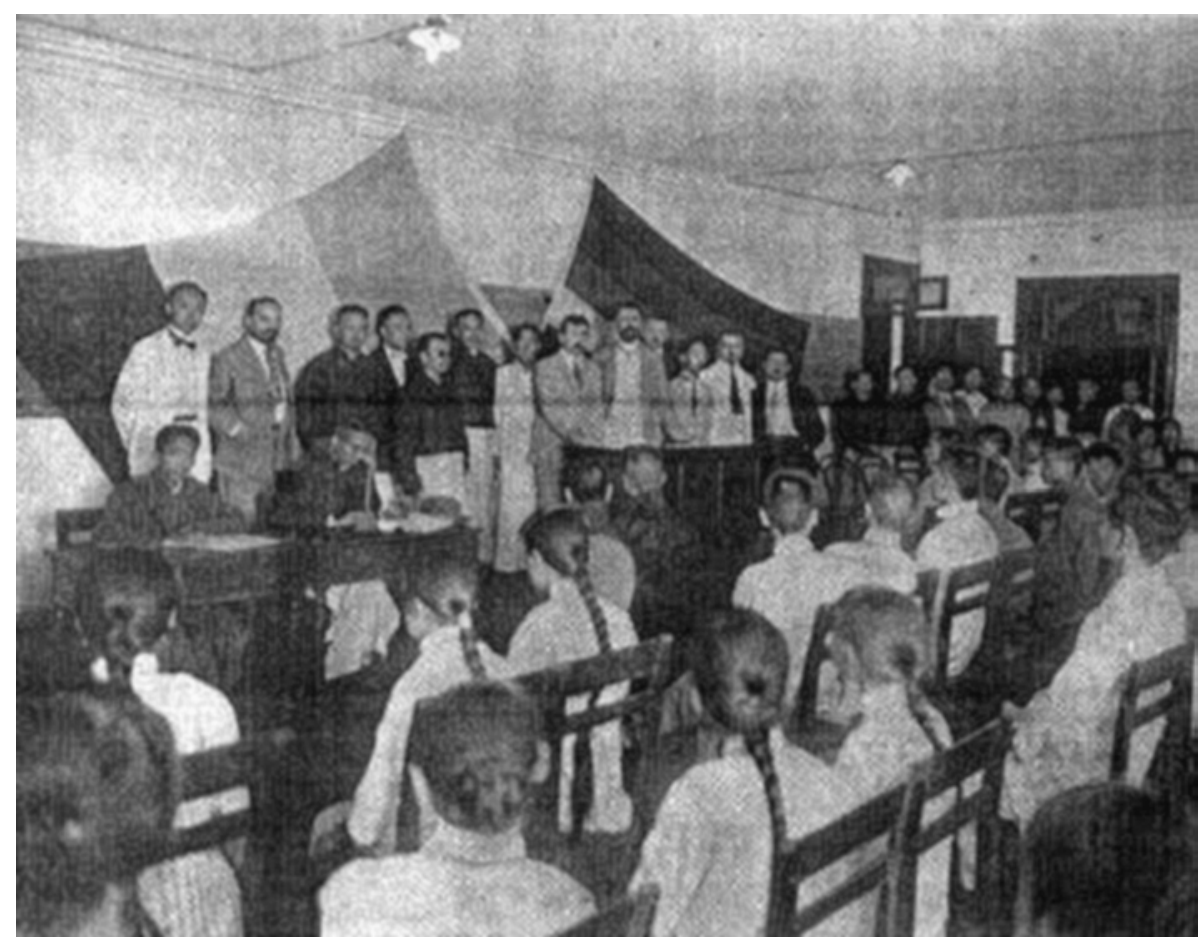

Figure 2. Painlevé and Borel speaking at the Chinese Society of Sciences in Shanghai, 1920. Photo courtesy of J.-C. Martzloff.

fied means to treat equations of different type, and so on.

Hadamard richly deserves to be called the founder and pioneer of the theory of linear partial differential equations of second order.

Hadamard was a universal scholar. Beside the theory of analytic functions, number theory, and the theory of partial differential equations, he made important contributions to the fields of functional analysis, theory of functions of real variables, algebra, probability theory, geometry, and topology. Not limiting himself to mathematics, he wrote also on mechanics, the psychology of education, the history of mathematics, and biology. He is said to have had an impressive collection of fern specimens.

Hadamard was a noble-minded scholar with a sense of justice, and a good friend of the Chinese people. He had actively taken part in the activities in Paris to support the Chinese anti-Japanese movement. His two elder sons were killed in the First World War; his youngest son was killed on the front line in North Africa in 1944. Hadamard was awarded the GrandCroix de la Légion d'honneur by the French President in 1957.

Hadamard graduated from l'École Normale Supérieur in 1888. Having received the degree of doctorat ès sciences mathématiques in 1892, he taught at Lycée Buffon in Paris, Université de Bordeaux, and Université de Paris in succession. He

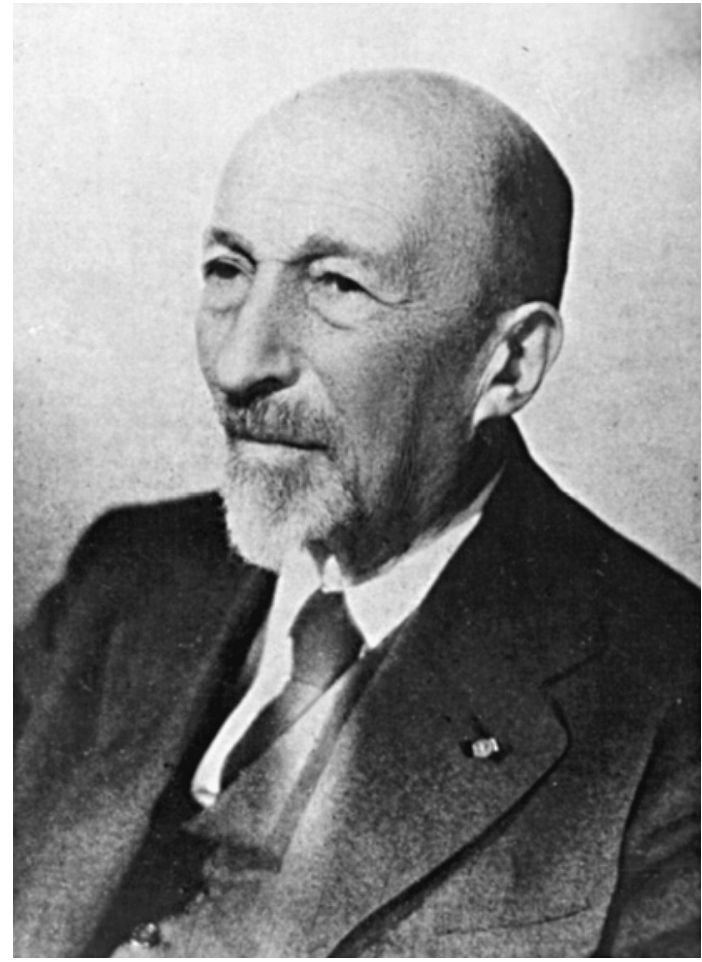

Figure 3. Jacques Hadamard.

was appointed Professor at the Collège de France in 1909 and held the position till his retirement in 1937. Hadamard was elected to the Académie des 
Sciences in 1912, succeeding Poincaré. He was a Fellow of the Royal Society of London and of the Royal Society of Edinburgh, and a member of the National Academy of Sciences in the U.S.A. He was also a member of the Academy of Sciences in the U.S.S.R., the Academia dei Lincei, and the Belgian, Brazilian, Dutch, Egyptian, Indian, Irish, Polish, and Swedish academies of science.

Hadamard retired from the Collège de France in the year following his visit to Tsinghua University.

\section{The Visit to Tsinghua University}

Hadamard's visit to Tsinghua was supported jointly by Tsinghua University and Sino-French Cultural Foundation, and was in fact orchestrated by King-Lai Hiong, chair of the department of mathematics of Tsinghua University, who, as mentioned above, had been to France twice to study mathematics.

Hadamard and his wife, Louise-Anna, arrived at Shanghai aboard the ship Asian Queen on March 22, 1936. Hadamard visited Academia Sinica, where the academy president Yuan-pei Tsai gave them a welcoming banquet. Hadamard was also invited, jointly by the Chinese Mathematical Society and the Chinese Society of Sciences, to give a public lecture at the Jiaotong University in Shanghai. From Shanghai, he paid a short visit to Japan and returned to China on April 7. Landed at the Tanggu Port, they changed to the train for Peking. At Peking, they were warmly welcomed by university president Y. C. Mei, by C. S. Ye, dean of the College of Science, and by K. L. Hiong, head of the department of mathematics. It was said that Hadamard walked in high spirits through the campus and spoke highly of the university.

Hadamard gave two series of lectures at Tsinghua. The first, a specialized course for teachers and senior students of the department of mathematics, and entitled "Sur le problème de Cauchy et les équations aux dérivées partielles linéaires," ran from April 10 and consisted of twenty lectures given twice weekly. The other was a public lecture series, intended for a more general audience, and entitled "Sur la géométrie anallagmatique."

It happened that Tsinghua University celebrated its 25th anniversary during Hadamard's visit. In the morning of April 26 Hadamard appeared at the commemoration ceremony, where he gave a public talk entitled "Some reflection on the role of mathematics," which was warmly received.

Hadamard's lectures at Tsinghua University concluded on June 25. Shortly before his return to France, the Academy of Sciences of Peking held a reception at the Institute of Physics to honor Professor and Madam Hadamard. More than forty mathematicians and physicists were present, among them Tsai-han
Kiang, Zu-xun Feng, Jin-yi Zhao, Yu-tai Rao, and Likui Yang. After the reception, the guests visited the Institute of Physics accompanied by director Ji-ci Yan, and the Institute of Chemistry accompanied by director Wei-tao Liu.

Hadamard's visit to Tsinghua overlapped by a few weeks with that of the American mathematician Norbert Wiener (1894-1964), who had arrived in August of 1935 and who left Peking in May of 1936. The two scholars' time together at Tsinghua is recalled in Wiener's autobiography I am a Mathematician.

\begin{abstract}
We... used to go down into the tangled, squalid streets of the so-called Chinese city (as opposed to the rectangular Tatar city) to rummage in the antique shops. There we would often come across ancestor portraits which showed dignified Chinese gentlemen or ladies, in stiff poses, with hands on the knees, dressed in marvelous silken gowns... We found one such ancestor portrait which was so like Professor Hadamard himself, with his somewhat sparse, stringy beard, his hooked nose, and his fine, sensitive features, that it would have been completely adequate to identify him and to pick him out of a large assembly of people... We bought this picture and gave it to its likeness. He appreciated it very much, but I don't think that Madame Hadamard care for it.
\end{abstract}

\section{Influence}

The visit of Wiener and Hadamard to Tsinghua University had a far-reaching influence on the development of mathematics in China. Their lectures introduced teachers and students to the current frontiers of mathematics. More important was their direct contact with young Chinese scholars, which led to the growing up of a group of outstanding mathematicians later on. As regards Hadamard, here are some examples of these scholars:

Loo-keng Hua (华罗庚, 1910-1985). Among the audience of Hadamard's lectures at Tsinghua was a young junior scholar possessing only a middle school diploma. His name was Loo-keng Hua, and several years before he had been called by King-lai Hiong to Tsinghua from Jintan, a remote county of Jiangsu province. Having been told that Hua was working on the Waring problem, Hadamard suggested that he pay attention to I. M. Vinogradov's work, and introduced him to Vinogradov by correspondence. That introduction was-like Wiener's introduction of Hua to G. Hardy-essential for Hua's academic future. In fact, it was Vinogradov who recommended Hua's monograph "Additive Number Theory" for publication in the Academy of Sciences of the U.S.S.R., which brought Hua an international reputation.

Chi-tai Chuang (庄圻泰, 1909-1998). Chi-tai Chuang entered Tsinghua in 1934 as a graduate student supervised by King-lai Hiong. Chuang attended Hadamard's lectures and passed the final examination with perfect solutions to problems posed by Hadamard himself. After obtaining his master's degree from Tsinghua University, Chuang was sent 


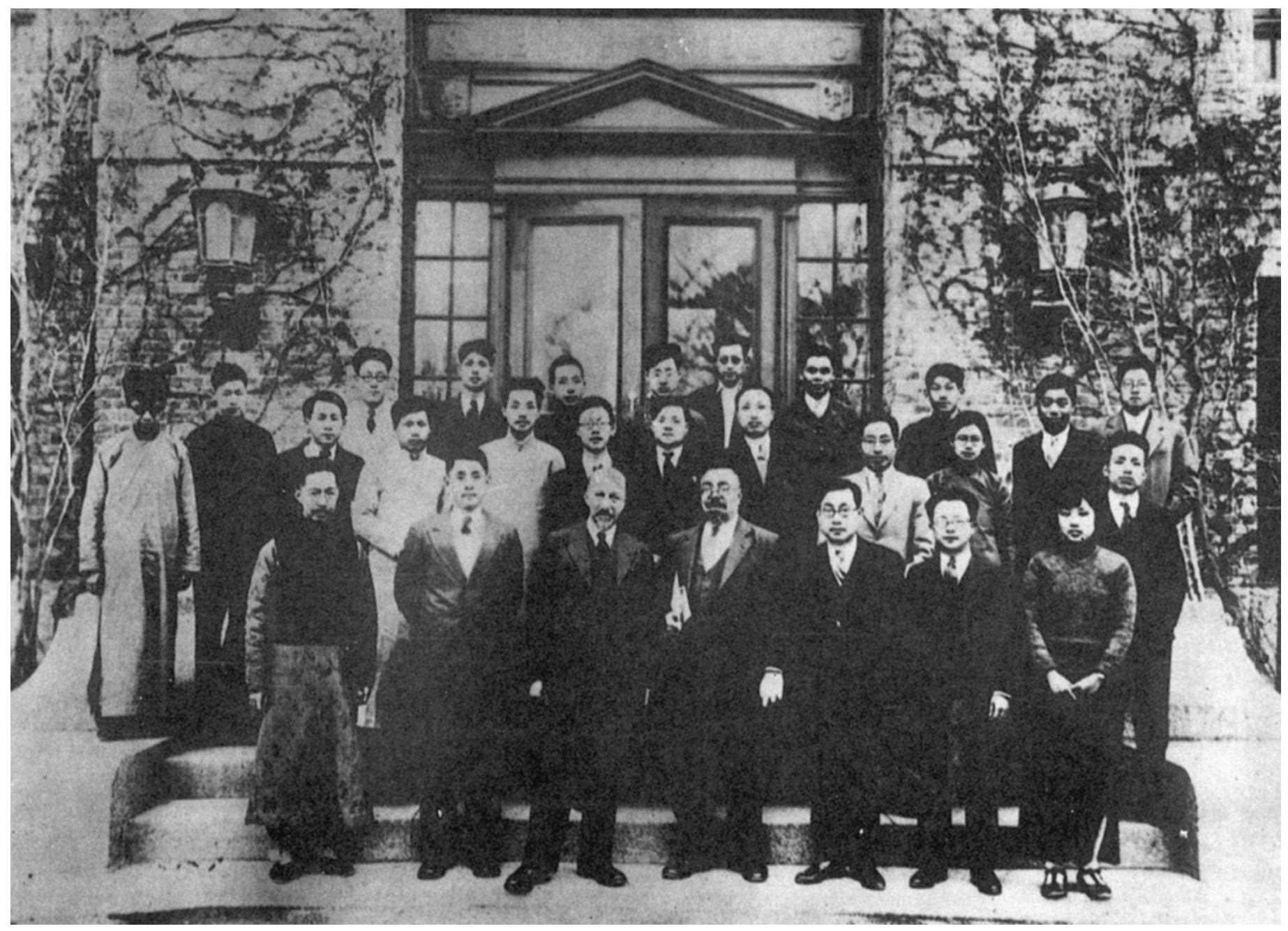

Figure 4. Hadamard with colleagues at the department of mathematics of Tsinghua University. Front row, left to right: Zhi-fan Zheng, Ko-Chuen Yang, Hadamard, N. Wiener, and K. L. Hiong.

to France at state expense and took the theory of meromorphic function as his major. Chuang was supervised by Professor G. Valiron at the Université de Paris, and participated regularly in the famous seminar conducted by Hadamard at the Collège de France, at which his dissertation was introduced to French colleagues. Chi-tai Chuang later became a leading expert in the field of theory of functions in China.

Sing-mo Ou (吴新谋, 1910-1989). Sing-mo Ou was without doubt in the audience at Hadamard's Tsinghua lectures and later developed a life-long friendship with Hadamard. He taught at the department of mathematics at Tsinghua University as an assistant professor from 1934 to 1937, and became interested in differential equations under the influence of Professor King-lai Hiong. Ou was sent to France at state expense in 1937, where he attended a class in viscous fluid mechanics and eventually changed his major to partial differential equations, under the supervision of Hadamard. In 1951, he returned to the People's Republic of China, where he became the founder of the undertaking of PDEs. His research work shows the deep influence of Hadamard's thought. He remained in contact with Hadamard even after China became isolated from the West. It was by Ou's recommendation that the Chinese Academy of Sciences signed a contract with Hadamard to publish his monograph "La théorie des équations aux dérivées partielles," an expanded and updated version of Hadamard's lecture notes given at Tsinghua University in 1936. Ou had served as the monograph's editor during his time in Paris.

When "La théorie des équations aux derives partielles" was published by Science Press, Beijing in November in 1964, Hadamard had already passed away. In his foreword to the book, Ou writes:

Le Professeur J. Hadamard, Membre de l'Institut de France et mathématician vénéré de notre époque, a apporté, comme chacun sait, une immense contribution à la théorie des équations aux derives partielles. Le Professeur J. Hadamard qui 


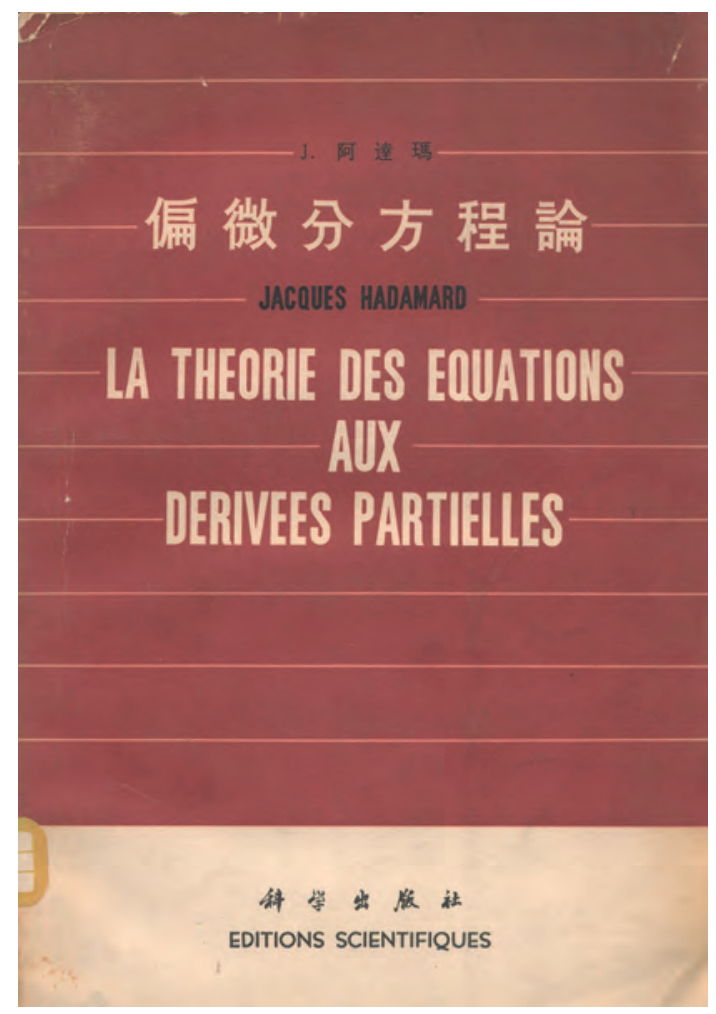

Figure 5. Cover of Hadamard's last work. (Courtesy of the Academy of Mathematics and Systems Science, Chinese Academy of Sciences.)

a plus de 90 ans a travaillé avec le plus grand courage à la redaction de cet ouvrage. Se fondant sur son traité "Le
Problème de Cauchy et les Equations aux dérivées partiells linéaires hyperboliques", devenu depuis longtemps un classique, l'Auteur traite largement et clairement des theories développées depuis la parution du dit traité, et notamment des résultats qu'il a obtenus, ces derniéres années.

Ayant toujours nourri une profonde amitié pour le peuple chinois, l'Auteur a bien voulu nous remettre, pour publication dans notre pays, le manuscrit de son ouvrage. Nous lui en sommes profondément reconnaissants. Au moment de mettre sous press, nous apprenons avec consternation et une profonde tristesse le décès du Professeur J.Hadamard et nous regrettons infiniment qu'il n'ait pu voir son oeuvre publiée.

\section{References}

Scientific News, Kexue (Science), vol. 20, nos. 2, 5, 7, 8 (1936). Hadamard, J. La théorie des équations aux dérivées partielles. Beijing: Science Press, 1964.

Li, Wenlin, and Martzloff, Jean-Claude. "Aperçu sur les échanges mathématiques entre la Chine et la France (1880-1949)." Archive for History of Exact Sciences, vol. 53, nos. 3/4, 181-200, Springer, 1998.

$\mathrm{Li}$, Wenlin, and Lu, Zhujia. "A Biography of Ou Sing-mo." In Biographies of Chinese Modern Mathematicians, vol. 4, 20-26. Bejing: Science Press, 1993.

Ou, Sing-mo. “A Biography of J. Hadamard.” In Biographies of World Famous Mathematicians, 1233-1239. Beijing: Science Press, 1995.

Ou, Sing-mo. "Speech at the Meeting in Commemoration of the 50th Anniversary of Hadamard's Visit to China," given 1985. Unpublished.

Wen, Guochun. "A Biography of Chuang Chi-tai." In Biographies of Chinese Modern Mathematicians, vol. 2, 141-149, Nanjing: Jiangsu Educational Press, 1995.

Wiener, N. I am a Mathematician. New York: Doubleday, 1956. 